NBER WORKING PAPER SERIES

\author{
FOREIGN EXCHANGE \\ VOLUME: SOUND AND FURY \\ SIGNIFYING NOTHING?
}

Richard K. Lyons

Working Paper No. 4984

\author{
NATIONAL BUREAU OF ECONOMIC RESEARCH \\ 1050 Massachusetts Avenue \\ Cambridge, MA 02138 \\ January 1995
}

Forthcoming in The Microstructure of Foreign Exchange Markets, Jeffrey Frankel, Giampaolo Galli, Alberto Giovannini (Eds.), University of Chicago Press. I thank the following for helpful comments: George Constantinides, Mark Flood, Jeff Frankel, Antonio Mello, Carol Osler, and seminar participants at Berkeley, LSE, Northwestern, NYU, UBC, the IMF, MIT, and The Microstructure of Foreign Exchange Markets conference. I also thank Jeff Bohn for valuable research assistance, and Merrill Lynch and Lasser Marshall for access to dealers/brokers while trading. Financial assistance from the National Science Foundation and the Berkeley Program in Finance is gratefully acknowledged. Any errors are my own. This paper is part of NBER's research program in International Finance and Macroeconomics. Any opinions expressed are those of the author and not those of the National Bureau of Economic Research.

(C) 1994 by Richard K. Lyons. All rights reserved. Short sections of text, not to exceed two paragraphs, may be quoted without explicit permission provided that full credit, including $(\subset$ notice, is given to the source. 


\title{
FOREIGN EXCHANGE \\ VOLUME: SOUND AND FURY \\ SIGNIFYING NOTHING?
}

\begin{abstract}
This paper examines whether currency trading volume is informative, and under what circumstances. Specifically, we use transactions data to test whether trades occurring when trading intensity is high are more informative - dollar for dollar - than trades occurring when intensity is low. Theory admits both possibilities, depending primarily on the posited information structure. We present what we call a hot-potato model of currency trading, which explains why low-intensity trades might be more informative. In the model, the wave of inventorymanagement trading among dealers following innovations in order flow generates an inverse relationship between intensity and information content. Empirically, low-intensity trades are more informative, supporting the hot-potato hypothesis.
\end{abstract}

Richard K. Lyons

Haas School of Business

University of California, Berkeley

Berkeley, CA 94720-1900

and NBER 


\section{Foreign Exchange Volume: Sound And Fury Signifying Nothing?}

\section{Introduction}

Volume in the spot foreign exchange (FX) market dwarfs that in any other financial market. But is all this trading informative? This paper provides some empirical evidence. At the broadest level, our results help to clarify why trading volume in this market is extraordinarily high. At a narrower level, we provide some sharp results regarding the relationship between the intensity of trading and the informativeness of trades.

Specifically, we provide results that discriminate between polar views of trading intensity, which we refer to as (1) the event-uncertainty view and (2) the hot-potato view. The event-uncertainty view holds that trades are more informative when trading intensity is high; the hot-potato view holds that trades are more informative when trading intensity is low. In general, theory admits both possibilities, depending primarily on the posited information structure.

To understand the event-uncertainty view, consider the work of Easley and O'Hara (1992). In contrast to earlier models where new information is known to exist, in Easley and O'Hara (1992) new information may not exist. That is, there is some probability, say $p$, of new information, and probability (1-p) of no new information. In the event of new information, there is some probability, say $q$, that an informed trader has received good news, and probability $(1-q)$ of having received bad news. They demonstrate that if there is no trade at time $t$ then a rational dealer raises the probability she attaches to the no-information event, and lowers the probability of news having occurred. Put differently, if trading intensity is low, an incoming trade of a given size induces a smaller update in beliefs since it is less 
likely to be signaling news. On the flipside, trades occurring when intensity is high should induce a larger update in beliefs.

To understand our term "the hot-potato view" - that trades are more informative when trading intensity is low - consider the ideas of Admati and Pfleiderer (1988). Key to their model is the presence of discretionary liquidity traders: in order to minimize the losses they suffer to informed traders, rational liquidity traders clump together in their trading. (The reason informed traders cannot fully offset this advantage to clumping is that information is short-lived.) Due to this clumping of liquidity traders, trades occurring when intensity is high tend to be less informative.

The metaphor of the hot-potato offers a link between discretionary liquidity trading and FX trading. FX dealers use the metaphor in referring to the repeated passage of idiosyncratic inventory imbalances from dealer to dealer following an innovation in customer order flow. These inter-dealer liquidity trades are clearly discretionary as to timing, hence the connection between discretionary liquidity trading and the hot-potato view of order-flow information. To clarify the hot-potato process, consider the following crude, but not unrealistic example. (Keep in mind that roughly $90 \%$ of FX trading is inter-dealer, a much higher share than in other multiple-dealer markets.) Suppose there are 10 dealers, all of whom are risk averse, and each currently with a zero net position. A customer sale of $\$ 10$ million worth of DM is accommodated by one of the dealers. Not wanting to carry the open position, the dealer calculates his share of this inventory imbalance - or $1 / 10$ th of $\$ 10$ million - calls another dealer, and unloads $\$ 9$ million worth of DM. The dealer receiving this trade then calculates his share of this inventory imbalance - or 1/10th of $\$ 9$ million - calls another dealer, and unloads $\$ 8.1$ million worth of DM. The hot-potato process continues. In the limit, the total inter-dealer volume generated from the $\$ 10$ million customer trade is: $\$ 9 \mathrm{~m} /(1-0.9)=\$ 90$ million. The 
resulting share of wholesale trading that is inter-dealer: $90 \%$, roughly matching the empirical share.

Here are two possible reactions to the example above, neither of which vitiates its message. Reaction one: shouldn't the multiplier be infinite since risk-averse dealers would not choose to retain any of the imbalance? The answer to this query is this: in equilibrium, price will adjust to induce dealers to hold some of the perceived excess supply. [The $10 \%$ rule of the example is a crude approximation of a much richer short-run clearing mechanism; see Lyons (1994) for an optimizing model in which hot-potato trading arises between dealers.] Reaction two: inter-dealer trades can reduce idiosyncratic inventory imbalances - which reduces idiosyncratic risk rather than simply bouncing it - and this will mute the multiplier. This is true, particularly if the trades are brokered. It is therefore more reasonable to think about the example in terms of net customer orders, rather than gross.

The role of time in the empirical microstructure literature has only recently emerged. Two important contributions are Hasbrouck (1991) and Hausman, Lo, and MacKinlay (1992). Hasbrouck decomposes the variance of stock price changes into trade-correlated and trade-uncorrelated components, and finds trades are more informative at the beginning of the trading day. Also working with stocks, Hausman et al test for exogeneity of the length of time between transactions, which they reject at conventional significance levels. However, they argue that their estimates do not change when endogeneity is accounted for via instrumental variables. On the basis of this, they forge ahead with the assumption of exogenous inter-transaction times.

Empirical microstructure work in FX has been constrained until recently by a lack of transaction-level data. The paper most closely related to the analysis here is Lyons (1993a), which introduces a transactions dataset that is a subset of the data 
used here (namely, dealt quotes only). That paper presents evidence supporting both of the two main branches of microstructure theory: the asymmetricinformation branch and the inventory-control branch. Though many papers have provided evidence supporting the asymmetric-information branch, little or no direct evidence had previously been found in support of the inventory-control branch [see for example Madhavan and Smidt (1991), Manaster and Mann (1993), and the overview in O'Hara (1994)]. The fact that they are both present provides further impetus for the application of microstructural models to the FX market. The application here extends previous work by addressing the informational subtleties of order flow.

The paper is organized as follows: Section 2 presents a model of transaction prices that includes a relationship between trading intensity and the information content of trades; Section 3 describes the data; Section 4 presents our results; and Section 5 concludes. 


\section{A Model in Which Time Matters}

The following model extends the model of Madhavan and Smidt (1991) by incorporating a role for inter-transaction time. As they do, we will exploit the model's ability to disentangle the information effects of trades from the inventory control effects. The result is a richer characterization of market depth.

There are two assets in a pure exchange economy: one riskless (the numeraire) and one with a stochastic liquidation value - representing FX. The FX market is organized as a decentralized dealership market with $n$ dealers. Here, we focus on the pricing behavior of a representative dealer, denoted dealer $i$. A period is defined by a transaction effected against dealer $i$ 's quote, with periods running from $\mathrm{t}=1,2, \ldots, T$. Let $j$ denote the dealer requesting $i$ 's quote in any period. Figure 1 summarizes the timing in each period:

\section{Figure 1}

Sequencing in each period

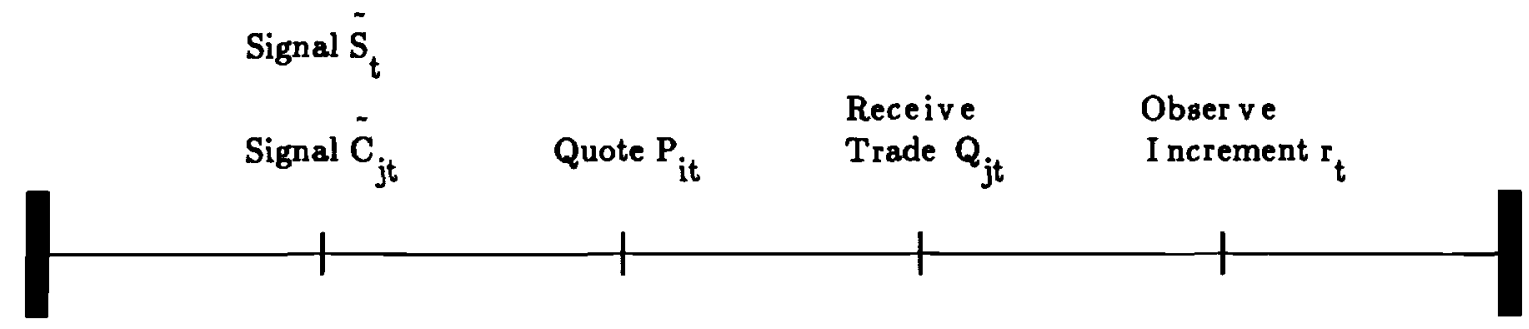

* Definitions: $\tilde{S}_{t}$ is a public signal of the full information value $\mathrm{V}_{t} ; \tilde{\mathrm{C}}_{j t}$ is dealer j's private signal of $v_{t}$, where $j$ denotes the dealer requesting the quote from dealer $i$; $P_{i t}$ is dealer i's bilateral quote to dealer $j$, a schedule matching each transaction quantity with a price; $Q_{j t}$ is the signed quantity traded, positive for dealer $j$ purchases, negative for sales; and $r_{t}$ is the period $t$ increment to $V_{t}$. 


\subsection{The Information Environment}

The full information price of FX at time $T$ is denoted by $\overrightarrow{\mathrm{V}}$, which is composed of a series of increments - e.g. interest differentials - so that $\bar{V}={ }_{i=0}^{T} \bar{r}_{i}$, where $r_{0}$ is a known constant. The increments are i.i.d. mean zero. Each increment $r_{t}$ is realized immediately after trading in period t. Realizations of the increments can be thought to represent the flow of public information over time. The value of FX at $t$ is thus defined as $V_{t}={ }_{i}^{t}=_{0} r_{i}$. At the time of quoting and trading in period $t$, i.e. before $\tilde{r}_{t}$ is realized, $\tilde{V}_{t}$ is a random variable. In a market without private information or transaction costs the quoted price of FX at time $t$, denoted $P_{t}$, would be equal to $V_{t-1}$, which is the expected value of the asset price conditional on public information available at $\mathrm{t}$.

The following two signals define each period's information environment prior to dealer i's quote to dealer $\mathrm{j}$ :

$$
\begin{gathered}
\tilde{S}_{t}=V_{t}+\tilde{\eta}_{t} \\
\tilde{C}_{j t}=v_{t}+\bar{\omega}_{j t}
\end{gathered}
$$

where the noise terms $\eta_{\mathrm{t}}$ and $\omega_{\mathrm{jt}}$ are normally distributed about zero, are independent of one another and across periods, and have variances $\sigma_{\eta}^{2}$ and $\sigma_{\omega}^{2}$ respectively. At the outset of each period $t$, all dealers receive a public signal $\mathbf{S}_{\mathbf{t}}$ of the full-information value $\mathrm{V}_{\mathrm{t}}$. Also at the outset of each period $t$, dealer $\mathrm{j}-$ the dealer requesting a quote - receives a private signal $\mathrm{C}_{\mathrm{jt}}$ of $\mathrm{V}_{\mathrm{t}}$. In the $\mathrm{FX}$ market, one potential source of private signals at the dealer level is order flow from non-dealer customers; because each dealer has sole knowledge of his own-customer order flow, to the extent this flow conveys information it is private information, which can be exploited in inter-dealer trading [see, for example, Goodhart (1988) 
page 456, and Lyons (1994)].

Dealer $i$ conditions on $S_{t}$, and then quotes his schedule as a function of $Q_{j t}$. The schedule's sensitivity to $Q_{j t}$ insures that any realization of $Q_{j t}$ will be regret-free for the quoting dealer, in the sense of Glosten and Milgrom (1985). That is, the quote takes account of the adverse selection arising from dealer j's additional information $\overline{\mathrm{C}}_{\mathrm{jt}}$. Of course, the realization of $\mathrm{Q}_{\mathrm{jt}}$ still provides dealer $i$ a signal of $\tilde{\mathrm{C}}_{\mathrm{jt}}$. As is standard, the signed quantity dealer $j$ chooses to trade is linearly related to the deviation between dealer $j$ 's expectation and the transaction price, plus a quantity representing liquidity demand $\mathrm{X}_{\mathrm{jt}}$ that is uncorrelated with $\mathrm{V}_{\mathrm{t}}$ :

$$
\mathrm{Q}_{\mathrm{jt}}=\theta\left(\mu_{\mathrm{jt}}-\mathrm{P}_{\mathrm{it}}\right)+\mathrm{X}_{\mathrm{jt}}
$$

where $\mu_{\mathrm{jt}}$ is the expectation of $\mathrm{V}_{\mathrm{t}}$ conditional on information available to dealer $j$ at $t$, and the value of $\mathrm{X}_{\mathrm{jt}}$ is known only to dealer $j$. [The demand function that supports equation (3) requires either exponential utility defined over a single period, or mean-variance optimization over multiple periods.]

We introduce a role for time in the model via equation (3) and the liquidity demand $\mathbf{X}_{\mathrm{jt}}$. The hot-potato hypothesis of order-flow information associates liquidity demand $\mathrm{X}_{\mathrm{jt}}$ with inventory-adjustment trading. In FX - according to the hypothesis - innovations in non-dealer order flow spark repeated inter-dealer trading of idiosyncratic inventory imbalances. This rapid passing of the hot-potato generates a relatively large role for liquidity trades in periods of short inter-transaction times. The event-uncertainty hypothesis, in contrast, associates short inter-transaction times with a relatively large role for informative trading: in the presence of event uncertainty, intense trading is a signal that an information event has occurred. To summarize, for given precisions of the signals $C_{j t}$ and $S_{t}$, we can characterize these views as: 
Hot-potato hypothesis: $\quad \sigma_{\mathrm{Xj}}^{2}\left\{\begin{array}{l}\text { high when inter-transaction times are short } \\ \text { low when inter-transaction times are long }\end{array}\right.$

Event-uncertainty hypothesis: $\sigma_{\mathrm{Xj}}^{2}\left\{\begin{array}{c}\text { low when inter-transaction times are short } \\ \text { high when inter-transaction times are long }\end{array}\right.$

This change in the relative intensity of liquidity trading will alter the signal extraction problem faced by the quoting dealer, to which we now turn.

\subsection{The Formation of Expectations}

Dealer $i$ 's quotes depend on his conditional expectation of $V_{t}$ at the time of quoting, which we denote $\mu_{i t}$. This expectation, in turn, is a function of the variables described above: $S_{t}$ and $Q_{j t}$; the third variable described above, $\tilde{C}_{j t}$, is communicated (noisily) to dealer $i$ via $Q_{j t}$.

We now address the determination of this expectation $\mu_{i t}$. Dealer $i$ 's prior belief regarding $V_{t}$ is summarized by the public signal $S_{t}$. Dealer $i$ then considers the "what if" of various possible $Q_{j t}$ 's. In particular, from any $Q_{j t}$ dealer $i$ can form the statistic $Z_{j t}$ (see appendix):

$$
\mathrm{Z}_{\mathrm{jt}} \equiv \frac{\mathrm{Q}_{\mathrm{jt}} / \theta+\mathrm{P}_{\mathrm{it}}-\lambda \mathrm{S}_{\mathrm{t}}}{1-\lambda}=\mathrm{V}_{\mathrm{t}}+\tilde{\omega}_{\mathrm{jt}}+[1 / \theta(1-\lambda)] \tilde{\mathrm{X}}_{\mathrm{jt}}
$$

where $\lambda \equiv \sigma_{\omega}^{2} /\left(\sigma_{\eta}^{2}+\sigma_{\omega}^{2}\right)$. This statistic is normally distributed, with mean $\mathrm{V}_{\mathrm{t}}$ and variance equal to the variance of the last two terms, both of which are orthogonal to $V_{t}$. Via $X_{j t}$, the variance of the second of these two terms is a function of inter-transaction times, per above. Let $\sigma_{\mathrm{Zs}}^{2}$ denote the variance of the statistic $\mathrm{Z}_{\mathrm{jt}}$ when inter-transaction times are short, and let $\sigma_{\mathrm{Zl}}^{2}$ denote the variance of $\mathrm{Z}_{\mathrm{jt}}$ when inter-transaction times are long.

Since $Z_{j t}$ is statistically independent of $S_{t}$, dealer i's posterior $\mu_{i t}$, expressed as a function of any $Q_{j t}$, takes the form of a weighted average of $S_{t}$ and $Z_{j t}$ : 


$$
\mu_{i t}=\kappa_{k} S_{t}+\left(1-\kappa_{k}\right) Z_{j t} \quad k=s, l
$$

where $\kappa_{\mathrm{s}} \equiv \sigma_{\mathrm{Zs}}^{2} /\left(\sigma_{\mathrm{Zs}}^{2}+\sigma_{\eta}^{2}\right)$ and $\kappa_{\mathrm{l}} \equiv \sigma_{\mathrm{Zl}}^{2} /\left(\sigma_{\mathrm{Zl}}^{2}+\sigma_{\eta}^{2}\right)$. This expectation plays a central role in determining dealer $i$ 's quote. Note that $\kappa_{s}>\kappa_{\mathrm{l}}$ if $\sigma_{\mathrm{Zs}}^{2}>\sigma_{\mathrm{Zl}}^{2}$, i.e., if liquidity trading is relatively important when inter-transaction times are short.

\subsection{The Determination of Bid/Offer Quotes}

Consider the following prototypical inventory-control model. Here, price is linearly related to the dealer's current inventory - a specification that is optimal in a number of inventory control models:

$$
\mathrm{P}_{\mathrm{it}}=\mu_{\mathrm{it}}-\alpha\left(\mathrm{I}_{\mathrm{it}}-\mathrm{I}_{\mathrm{i}}^{*}\right)+\gamma \mathrm{D}_{\mathrm{t}}
$$

where $\mu_{\mathrm{it}}$ is the expectation of $\mathrm{V}_{\mathrm{t}}$ conditional on information available to dealer $i$ at $t, \mathbf{I}_{i t}$ is dealer $i$ 's current inventory position, and $\mathrm{I}_{i}^{*}$ is $i$ 's desired position. The inventory-control effect, governed by $\alpha$, will in general be a function of relative interest rates, firm capital, and carrying costs. The variable $D_{t}$ is a direction-indicator variable with a value of 1 when a buyer-initiated trade occurs, and a value of -1 when a seller-initiated trade occurs. The term $\gamma D_{t}$ then picks up (half of) the effective spread: if dealer $j$ is a buyer then the realized transaction price $\mathrm{P}_{\mathrm{it}}$ will be on the offer side, and therefore a little higher, ceteris paribus. This term can be interpreted as compensation resulting from execution costs, price discreteness, or rents.

Consistent with the regret-free property of quotes, we substitute dealer i's expectation conditional on possible $Q_{j t}$ 's - equation (5) - into equation (6), yielding: 


$$
\mathrm{P}_{\mathrm{it}}=\kappa_{\mathrm{k}} \mathrm{S}_{\mathrm{t}}+\left(1-\kappa_{\mathrm{k}}\right) \mathrm{Z}_{\mathrm{jt}}-\alpha\left(\mathrm{I}_{\mathrm{it}}-\mathrm{I}_{\mathrm{i}}^{*}\right)+\gamma \mathrm{D}_{\mathrm{t}} \quad \mathbf{k}=\mathrm{s}, 1
$$

which is equivalent to (see appendix):

$$
P_{i t}=S_{t}+\left[\frac{1-\phi_{k}}{\phi_{k} \theta}\right] Q_{j t}-\left[\frac{\alpha}{\phi_{k}}\right]\left(I_{i t}-I_{i}^{*}\right)+\left[\frac{\gamma}{\phi_{k}}\right] D_{t}
$$

where $\phi_{\mathbf{k}} \equiv\left(\kappa_{\mathbf{k}}-\lambda\right) /(1-\lambda)$ and $0<\phi_{\mathbf{k}}<1$ since $0<\kappa_{\mathbf{k}}<1,0<\lambda<1$, and $\kappa_{\mathbf{k}}>\lambda$.

\subsection{An Estimable Equation}

Equation (8) is not directly estimable because $S_{t}$ is not observable to the econometrician. Our assumptions about the signals available and the evolution of $\mathrm{V}_{\mathrm{t}}$ allow us to express the period $t$ prior $\mathrm{S}_{\mathrm{t}}$ as equal to the period $t-1$ posterior from equation (6) lagged one period, plus an expectational error term $\epsilon_{\mathrm{it}}$ :

$$
\mathrm{S}_{\mathrm{t}}=\mu_{\mathrm{it}-1}+\epsilon_{\mathrm{it}}=\mathrm{P}_{\mathrm{it}-1}+\alpha\left(\mathrm{I}_{\mathrm{it}-1}-\mathrm{I}_{\mathrm{i}}^{*}\right)-\gamma \mathrm{D}_{\mathrm{t}-1}+\epsilon_{\mathrm{it}} .
$$

Substituting this expression for $S_{t}$ into equation (8) yields:

$$
P_{i t}=\left[P_{i t-1}+\alpha\left(I_{i t-1}-I_{i}^{*}\right)-\gamma D_{t-1}+\epsilon_{i t}\right]+\left[\frac{1-\phi_{k}}{\phi_{k} \theta}\right] Q_{j t}-\left[\frac{\alpha}{\phi_{k}}\right]\left(I_{i t}-I_{i}^{*}\right)+\left[\frac{\gamma}{\phi_{k}}\right] D_{t} .
$$

which implies:

$$
\Delta \mathrm{P}_{\mathrm{it}}=\left[\frac{\alpha}{\phi_{\mathrm{k}}}-\alpha\right] \mathrm{I}_{\mathrm{i}}^{*}+\left[\frac{1-\phi_{\mathrm{k}}}{\phi_{\mathrm{k}} \theta}\right] \mathrm{Q}_{\mathrm{jt}}-\left[\frac{\alpha}{\phi_{\mathrm{k}}}\right] \mathrm{I}_{\mathrm{it}}+\alpha \mathrm{I}_{\mathrm{it}-1}+\left[\frac{\gamma}{\phi_{\mathrm{k}}}\right] \mathrm{D}_{\mathrm{t}}-\gamma \mathrm{D}_{\mathrm{t}-1}+\epsilon_{\mathrm{it}} .
$$

This corresponds to a reduced form estimating equation of: 


$$
\Delta \mathrm{P}_{\mathrm{it}}=\beta_{0}+\beta_{1} \mathrm{Q}_{\mathrm{jt}}+\beta_{2} \mathrm{I}_{\mathrm{it}}+\beta_{3} \mathrm{I}_{\mathrm{it}-1}+\beta_{4} \mathrm{D}_{\mathrm{t}}+\beta_{5} \mathrm{D}_{\mathrm{t}-1}+\epsilon_{\mathrm{it}}
$$

Thus, the change in the transaction price from $t-1$ to $t$ is linearly related to: (i) the signed incoming order at $t$, (ii) the inventory level at $t$, (iii) the inventory level at $t-1$, (iv) whether $P_{i t}$ is at the bid or offer, and (v) whether $P_{i t-1}$ is at the bid or offer. Note that the last two regressors - the indicator variables $D_{t}$ and $D_{t-1}$ - are accounting for bid-offer bounce. The model predicts that $\left\{\beta_{1}, \beta_{3}, \beta_{4}\right\}>0,\left\{\beta_{2}, \beta_{5}\right\}<0$, $\left|\beta_{2}\right|>\beta_{3}$, and $\beta_{4}>\left|\beta_{5}\right|$, irrespective of the inter-transaction time. (The latter inequalities derive from the fact that $0<\phi_{k}<1$.) These more general predictions are borne out in the data, and are presented in Lyons (1993a). Here, our focus is on the information in order flow measured by $\beta_{1}$, which is in turn a function of our structural parameter $\kappa$ from equation (5). That is, we want to test whether the coefficient $\beta_{1}$ is sensitive to inter-transaction time, and if so, in which direction. The hot-potato hypothesis predicts a lower $\beta_{1}$ when inter-transaction times are short; the event-uncertainty hypothesis predicts a higher $\beta_{1}$ when inter-transaction times are short. These predictions derive from the relative importance of liquidity trading $\left(\sigma_{\mathrm{Xj}}^{2}\right)$ in the signal extraction problem.

Our final comment on the model concerns the assumption of a time-invariant desired inventory. First, note that with a slight re-interpretation the model can accommodate variability in desired inventories, that is, an $I_{i}^{*}$ that varies through time. Consider the following model: $I_{i t}^{*}=I_{i}+\delta\left(\mu_{i t}-S_{t}\right)$, which is consistent with the linear demands arising from negative exponential utility, where the public information $S_{t}$ represents the market price away from dealer $i$. Further, $Q_{j t}$ is the only information available to dealer $i$ that is not reflected in $S_{t}$. Under the assumptions of our model, $\left(\mu_{\mathrm{it}}-S_{\mathrm{t}}\right)$ is proportional to $\mathrm{Q}_{\mathrm{jt}}$. Accordingly, we write $\left(\mu_{\mathrm{it}}-\mathrm{S}_{\mathrm{t}}\right)=\pi \mathrm{Q}_{\mathrm{jt}}$. Hence, we can express the desired inventory as: $\mathrm{I}_{\mathrm{it}}^{*}=\mathrm{I}_{\mathrm{i}}+\delta \pi \mathrm{Q}_{\mathrm{jt}}$. In estimation, $I_{i}$ is absorbed in the constant. The estimate of $\beta_{1}$ now represents 
$\left[\frac{1-\phi_{k}}{\phi_{k} \theta}\right] Q_{j t}+\left[\frac{\alpha}{\phi_{k}}-\alpha\right] \delta \pi$, whose significance still evinces an information effect, though we have to be more careful in interpreting its magnitude.

\section{Data}

Our dataset has significant advantages over FX data used in the past, in particular Reuters indications data [see for example Goodhart (1989), and Bollerslev and Domowitz (1993)]. The main shortcomings of the Reuters indications are three: first, these are only indications, not firm quotes at which dealers can transact; second, there is no measure of order flow or transaction prices; and third, the spreads in the indications dataset are 2 to 3 times the size of firm quotes in the inter-dealer market.

Our dataset consists of two linked components, covering the five trading days of the week August 3-7, 1992, from the informal start of trading at 8:30 EST to roughly 1:30 EST. The first component includes the time-stamped quotes, prices, and quantities for all the direct inter-dealer transactions of a single DM/ $/ \mathbb{S}$ dealer at a major New York bank. The second component comprises the same dealer's position cards, which includes all indirect (brokered) trades.

\subsection{Dealer Data: Direct Quotes and Trades}

The first component of the dataset includes the dealer's quotes, prices, and quantities for all direct transactions. The availability of this component is due to a recent change in technology in this market: the Reuters Dealing 2000-1 system. This system - very different from the system that produces the Reuters indications - allows dealers to communicate quotes and trades bilaterally via computer rather than verbally over the telephone. 1 Among other things, this allows dealers to

\footnotetext{
1 Dealing 2000-1 is also very different than Dealing 2000-2. The former is wholly bilateral, while the latter is akin to an electronic broker, where multiple dealers participate.
} 
request up to four quotes simultaneously, whereas phone requests are necessarily sequential. Another advantage is that the computerized documentation reduces the paperwork required of the dealers. Though use of this technology differs by dealer and is currently diffusing more widely, our dealer uses Dealing 2000-1 for nearly all of his direct interbank trades: less than $0.4 \%$ of all transactions were done over the phone over our sample week (as indicated on the position cards).

Each record of the data covering the dealer's direct trading includes the first 5 of the following 7 variables; the last two are included only if a trade takes place:

(1) The time the communication is initiated (to the minute, with no lag).

(2) Which of the two dealers is requesting the quote.

(3) The quote quantity.

(4) The bid quote.

(5) The offer quote.

(6) The quantity traded, (which provides $Q_{j t}$ ).

(7) The transaction price (which provides $\mathrm{P}_{i t}$ ). This component of the dataset includes 952 transactions amounting to $\$ 4.1$ billion.

Figure 2 provides an example of a dealer communication as recorded by the Dealing 2000-1 printout [see Reuters (1990) for more details]. The first word indicates that the call came "From" another dealer. Then comes the institution code and name of the counterparty, followed by the time (Greenwich Mean, computer assigned), the date (day first), and the number assigned to the communication. On line 3, "SP DMK 10" identifies this as a request for a spot $\mathrm{DM} / \$$ quote for up to $\$ 10$ million. Line 4 provides the quoted bid and offer price: typically, dealers only quote the last two digits of each price, the rest being superfluous in such a fast-moving market. These two quotes correspond to a bid of $1.58 \underline{8 \mathrm{D}} \mathrm{DM} / \$$ and an offer of $1.58 \underline{\mathrm{g}} \mathrm{DM} / \mathrm{\$}$. In confirming the transaction, the communication record provides the first three digits. Here, the calling dealer buys 
$\$ 10$ million at the $\mathrm{D}$-mark offer price of 1.5891 . The record confirms the exact price and quantity. In our dataset, transactions never take place within the spread; the transaction price always equals either the bid or the offer.

\section{Figure 2}

Example of a Reuters Dealing 2000-1 Communication

\footnotetext{


From CODE FULL NAME HERE * 1250GMT $030892 * / 1080$

Our Terminal : CODE Our user : DMK

SP DMK 10

\# 8891

BUY

\# 10 MIO AGREED

\# VAL 6AUG92

\# MY DMK TO FULL NAME HERE

\# TO CONFIRM AT 1.5891 I SELL 10 MIO USD

\#

TO CONFIRM AT 1.5891 I SELL 10 MIO USD

VAL 6AUG92

MY USD TO FULL NAME HERE AC 0-00-00000

THKS N BIFN

\# \#END LOCAL\#

\#

\#\# WRAP UP BY DMK DMK 1250GMT 3AUG92

\#END\#

( 265 CHARS)

* "From" establishes this as an incoming call; the caller's four-digit code and institution name follow; "GMT" denotes Greenwich Mean Time; the date follows, with the day listed first; "SP DMK $10 "$ identifies this as request for a spot, DM/\$ quote for up to $\$ 10$ million; "8891" denotes a bid of 88 and an offer of 91 (only the last two digits are quoted); the confirmation provides the complete transaction price, and verifies the transaction quantity.
}

\subsection{Dealer Data: Position Cards}

The second component of the dataset is composed of the dealer's position cards

over the same five days covered by the direct-transaction data, August 3-7, 1992. 
In order to track their positions, spot dealers record all transactions on handwritten position cards as they go along. An average day consists of approximately 20 cards, each with about 15 transaction entries.

There are two key benefits to this component of the dataset. First, it provides a very clean measure of the dealer's inventory $I_{t}$ at any time since it includes both direct trades and any brokered trades. Second, it provides a means of error-checking the first component of the dataset.

Each card includes the following information for every trade:

(1) The signed quantity traded (which determines $I_{t}$ ),

(2) The transaction price, and

(3) The counterparty, including whether brokered.

Note that the bid/offer quotes at the time of the transaction are not included so this component of the dataset alone is not sufficient for estimating our model. Note also that each entry is not time-stamped; at the outset of every card, and often within the card too, the dealer records the time to the minute. Hence, the exact timing of some of the brokered transactions is not pinned down since these trades do not get confirmed via a Dealing 2000-1 record. Nevertheless, this is not a drawback for our purposes: the observations for our empirical model are the direct transactions initiated at our dealer's quoted prices; since the timing of these is pinned down by the Dealing 2000-1 records, and since these transactions appear sequentially in both components, the intervening changes in inventory due to brokered trades can be determined exactly.

\subsection{Descriptive Statistics}

Table 1 presents the data in the form of daily averages to convey a sense of the typical day's activity. This is masking some daily variation in the sample: the heaviest day $(8 / 7 / 92)$ is a little less than twice as active as the lightest day $(8 / 5 / 92)$. Note that this dealer averages well over $\$ 1$ billion of inter-dealer trading 
daily (brokered trades are necessarily inter-dealer). With respect to quoting, because our dealer is among the larger in this market, he has $\$ 10$ million "relationships" with many other dealers; that is, quote requests from other high-volume dealers that do not specify a quantity are understood to be good for up to $\$ 10$ million. Note the tightness of the median spread. For comparison, the median spread in the Reuters indications dataset is DM 0.001, more than three times as large. A bid/offer spread of 3 pips is less than $0.02 \%$ of the spot price.

Table 1 Here

A natural concern is whether our dealer is representative of the larger dealers in the spot market. While we cannot answer this definitively, we offer a few relevant facts. First, he has been trading in this market for many years and is well-known among the other major dealers. Second, in terms of trading volume he is without a doubt one of the key players, trading well over $\$ 1$ billion per day and maintaining $\$ 10$ million quote relationships with a number of other dealers. Though this would probably not put him in the top five in terms of volume, he is not far back, possibly in the 5th to 15th range somewhere. In the end, our view is that he is representative, at least with respect to the issues addressed here. There is no doubt, however, that different trading styles exist.

\subsection{Relevant Institutional Background}

Here, we highlight two institutional factors relevant to our analysis: (i) trading limits imposed on dealers and (ii) trading on the IMM futures market. As for trading limits, there is an important distinction between intraday limits and overnight limits. At our dealer's bank, which is typical of major banks, there are no explicit intraday limits on senior dealers, though dealers are expected to communicate particularly large trades to their immediate supervisor (about $\$ 50$ million and above for many banks in the current DM $/ \$$ market). In contrast, most banks impose overnight limits on their dealers. Currently, a common overnight 
limit on a single dealer's open position is about $\$ 75$ million, considerably larger than the largest open position in our sample. Most dealers, however, close their day with a zero net position; carrying an open position means monitoring it through the evening, an unattractive prospect after a full day of trading. Our dealer ended his day with a zero net position each of the five days in our sample. Finally, though broader risk-management programs are in place at the bank for which our dealer trades, it is rare in FX that a dealer's position is hedged because it aggregates unfavorably with others; and when this does occur, it is typically without the participation of the individual dealer.

As for trading on the IMM futures market while dealing spot, this differs by dealer. We stress, though, that unlike equity markets, the spot FX market is many times larger than the futures market: in 1992 the average daily volume in New York in spot DM $/ \$$ was roughly $\$ 50$ billion [New York FED (1992), adjusted for double counting]; in the same year the average daily volume on all IMM DM $/ \$$ contracts was less than $\$ 5$ billion. As for our dealer, his position cards show that he traded less than $\$ 1$ million daily in futures over the sample period, which is negligible relative to his daily spot volume. Like other spot dealers, he does listen to an intercom that communicates futures prices. However, this intercom is less important to a spot dealer than the intercoms connected to inter-dealer brokers in the spot market.

\section{Estimation Results}

We begin with our results from direct estimation of the model in equation (11), which are presented in Table 2. Though these estimates do not include any role for inter-transaction time, they provide a benchmark for the later results regarding the hot-potato and event-uncertainty hypotheses. Note that these estimates are essentially a replication of a result presented in Lyons (1993a). Accordingly, we 
refer readers to that earlier work for more detailed interpretation.

Table 2 Here

Given these benchmark results, henceforth we present only those coefficients which bear on the information content of order flow - namely variations of $\beta_{1}$ from equation 11. All non-reported coefficients remain significant at at least the $5 \%$ level, with the predicted signs and relative magnitudes. Presenting the results this way allows us to focus on the informational subtleties outlined in section 2 .

\subsection{The Core Model of Trading Intensity}

Table 3 presents our estimates of the information content of order flow, distinguishing between short and long inter-transaction times. This is achieved via the introduction of dummy variables $s_{t}$ and $l_{t}$ (see the equation heading the table). The dummy $s_{t}$ equals 1 if inter-transaction time is short, 0 otherwise; the dummy $l_{t}$ equals 0 if inter-transaction time is short, 1 otherwise. Short inter-transaction times are defined two ways: less than 1 minute from the previous transaction and less than 2 minutes. The time stamps on our data are very precise, since they are assigned by the computer; however, they do not provide precision beyond the minute. Hence, less than 1 minute includes trades with the same time stamp; less than 2 minutes includes trades with time stamps differing by 1 minute or less. These categories bracket the mean inter-transaction time of 1.8 minutes. The second category corresponds to a break at the median inter-transaction time.

Table 3 Here

The results provide strong support for the hot-potato hypothesis over the event-uncertainty hypothesis. The coefficient $\beta_{1}-$ which measures the information effect of incoming trades with short inter-transaction times - is insignificant at conventional levels. In contrast, the coefficient $\beta_{1}^{\prime}-$ which measures the information effect of incoming trades with long inter-transaction times - is 
significant. Moreover, a test of the restriction that $\beta_{1}=\beta_{1}^{\prime}$ is rejected at the $1 \%$ level in both cases. In summary, trades occurring when transaction intensity is high are significantly less informative than trades occurring when transaction intensity is low. This is the main result of the paper.

\subsection{The Pattern of the Market}

There is an additional testable implication of the hot-potato hypothesis: it follows directly from the story of bouncing inventories outlined in section 1 that these discretionary liquidity trades will tend to be in the same direction (i.e., have the same sign). The obverse is that clumped trading is more likely to be hotpotato (liquidity) trading if trades follow in the same direction. The implication for prices is that, even if Martingales, they are not necessarily Markov.

The test presented in Table 4 addresses this question: Is clumped order-flow less informative when transactions follow the same direction? Again, we introduce dummy variables, in this case $s_{t}, o_{t}$, and $l_{t}$ (see the equation heading the table). The dummy $s_{t}$ equals 1 if (i) inter-transaction time is short and (ii) the previous incoming trade has the same direction, 0 otherwise; the dummy $o_{t}$ equals 1 if (i) inter-transaction time is short and (ii) the previous incoming trade has the opposite direction, 0 otherwise; the dummy $l_{t}$ equals 0 if inter-transaction time is short, 1 otherwise. A short inter-transaction time is defined as less than the median of 2 minutes.

\section{Table 4 Here}

Once again, the results support the hot-potato hypothesis. The coefficient $\beta_{1}-$ short inter-transaction times and same direction - is insignificant. In contrast, the coefficient $\beta_{1}^{\prime}$ - short inter-transaction times and opposite direction - is significant. A test of the restriction that $\beta_{1}=\beta_{1}^{\prime}$ is rejected at the $1 \%$ level. To summarize, clumped trades occurring in the same direction are significantly less 
informative than clumped trades occurring in the opposite direction.

\subsection{Another Measure of Market Pace: Quote Intensity}

The results of Table 4 highlight another important observation: though the hot-potato and event-uncertainty hypotheses make opposite predictions regarding the relation between information and trading intensity, they are not necessarily competing hypotheses. That is, both effects could be operative: hot-potato trading simply dominates when trading is most intense in this market.

To examine whether there is independent support for event-uncertainty, we exploit an "instrument" that is arguably more closely related to event-uncertainty than inventory-control. To understand this instrument, recognize that in Easley and O'Hara (1992) transaction intensity per se is the only dimension of trading intensity available for signalling the underlying state. The problem for our purposes is that transaction intensity is also the linchpin of the hot-potato model. Our dataset, on the other hand, includes a second dimension of trading intensity: quoting intensity. The roughly 4:1 ratio of not-dealt quotes to dealt quotes in Table 1 indicates that transactions alone may not be telling the full story. More important for discriminating event-uncertainty from hot-potato is the fact that quote requests per se typically signal heightened uncertainty and information gathering, whereas hot-potato transactions minimize on quote requests in order to unload inventory rapidly. In short, quoting intensity provides another vehicle for Easley and O'Hara.

Table 5 presents estimates of the information content of order flow, distinguishing between high and low quoting intensity as a measure of market pace. Once again we introduce dummy variables, in this case $h_{t}$ and $l_{t}$ (see the equation heading the table). The dummy $h_{t}$ equals 1 if the total number of intervening quotes per minute is high, 0 otherwise; the dummy $l_{t}$ equals 0 if the total number of intervening quotes per minute is high, 1 otherwise. The different definitions of a 
high number of intervening quotes appear in column one. These quotes are from the Dealing 2000-1 portion of the dataset, described in subsection 3.1.

Table 5 Here

These results provide support for the event-uncertainty hypothesis. The coefficient $\beta_{1}$ reflecting high quoting intensity is significant, whereas the coefficient $\beta_{1}^{\prime}$ reflecting low quoting intensity is insignificant. A test of the restriction that $\beta_{1}=\beta_{1}^{\prime}$ is rejected at the $5 \%$ level in all three cases. To summarize, trades occurring when trading intensity is high - where trading intensity is proxied by quoting intensity - are significantly more informative than trades occurring when trading intensity is low.

\section{Conclusions}

Our results suggest that in FX: trading begets trading. The trading begotten is relatively uninformative, arising from repeated passage of idiosyncratic inventory imbalances among dealers. Clearly, this could not arise under a specialist microstructure. A broad implication is that a microstructural understanding of this market requires much richer multiple-dealer theory than now exists.

Our principal empirical findings are the following:

(1) Trades occurring when transaction intensity is high are significantly less informative than trades occurring when transaction intensity is low.

(2) Clumped trades occurring in the same direction are significantly less informative than clumped trades occurring in the opposite direction.

(3) Trades occurring when trading intensity is high - where trading intensity is proxied by quoting intensity - are significantly more informative than trades occurring when trading intensity is low.

We interpret results (1) and (2) as supportive of hot-potato trading among dealers 
in FX. We interpret result (3) as supportive of the Easley and O'Hara eventuncertainty hypothesis, though the vehicle differs from the transaction-focus of their paper. Taken together, the results highlight the potential complementarity between these seemingly polar views.

There is an important hardship in focusing on a dealership market like FX that warrants recognition. Empirical work on the specialist structure has the luxury of describing the behavior of a lone dealer. It is much more difficult to argue that by documenting the behavior of a single dealer in the FX market we have similarly captured the FX market. The data required to generate a more complete picture are out of the question given current availability. Nevertheless, the dealer we have tracked is without a doubt one of the key players in this market, trading well over $\$ 1$ billion per day and maintaining $\$ 10$ million quote relationships with a number of other dealers. Is he representative of dealers in the core of the wholesale spot market? We would argue yes, at least with respect to the issues addressed here. But, there is no doubt that different dealers have different trading styles. 


\section{References}

Admati, A., and P. Pfleiderer (1988): "A Theory of Intraday Patterns: Volume and Price Variability," Review of Financial Studies, 1: 3-40.

Amihud, Y., and H. Mendelson (1980): "Dealership Market: Market Making with Inventory," Journal of Financial Economics, 8: 31-53.

Bessembinder, H. (1994): "Bid-Ask Spreads in the Interbank Foreign Exchange Markets," Journal of Financial Economics, 35: 317-348.

Bollerslev, T., and I. Domowitz (1993): "Trading Patterns and Prices in the Interbank Foreign Exchange Market," Journal of Finance, 48: 1421-1444.

Easley, D., and M. O'Hara (1987): "Price, Quantity, and Information in Securities Markets," Journal of Financial Economics, 19: 60-90.

Easley, D., and M. O'Hara (1992): "Time and the Process of Security Price Adjustment," Journal of Finance, 47: 577-605.

Flood, M. (1992): "Market Structure and Inefficiency in the Foreign Exchange Market," Journal of International Money and Finance, 13: 131-158.

Foster, D., and S. Vishwanathan (1990): "Variations in Volumes, Variances, and Trading Costs," Duke University Working Paper \#88-108.

Garman, M. (1976): "Market Microstructure," Journal of Financial Economics, 3: 257-275.

Glosten, L., and L. Harris (1988): "Estimating the Components of the Bid-Ask Spread," Journal of Financial Economics, 21: 123-142.

Glosten, L., and P. Milgrom (1985): "Bid, Ask, and Transaction Prices in a Specialist Market with Heterogeneously Informed Agents," Journal of Financial Economics, 14: 71-100.

Goodhart, C. (1988): "The Foreign Exchange Market: A Random Walk With a Dragging Anchor," Economica, 55: 437-460.

Goodhart, C. (1989): "News' and the Foreign Exchange Market," Manchester Statistical Society Paper, October 17.

Goodhart, C., and L. Figliuoli (1991): "Every Minute Counts in Financial Markets," Journal of International Money and Finance, 10: 23-52.

Hasbrouck, J. (1988): "Trades, Quotes, Inventories, and Information," Journal of Financial Economics, 22: 229-252.

Hasbrouck, J. (1991): "The Summary Informativeness of Stock Trades: An Econometric Analysis," Review of Financial Studies, 4: 571-595. 
Hausman, J., A. Lo, and C. MacKinlay (1992): "An Ordered Probit Analysis of Transaction Stock Prices," Journal of Financial Economics, 31: 319-379.

Ho, T., and H. Stoll (1983): "The Dynamics of Dealer Markets Under Competition," Journal of Finance, 38: 1053-1074.

Kyle, A. (1989): "Informed Speculation with Imperfect Competition," Review of Economic Studies, 56: 317-356.

Laux, P. (1991): "Dealer Market Structure and the Bid-Ask Spread: Theory and Empirical Evidence," mimeo, University of Texas at Austin.

Lee, C., and M. Ready (1991): "Inferring Trade Direction from Intradaily Data," Journal of Finance, 46: 733-746.

Lyons, R. (1994): "Information Externalities in the Microstructure of the Foreign Exchange Market," Berkeley Business School manuscript, revised version of NBER Working Paper \#3889, October 1991.

Lyons, R. (1993a): "Tests of Microstructural Hypotheses in the Foreign Exchange Market," NBER Working Paper \#4471, forthcoming in the Journal of Financial Economics.

Lyons, R. (1993b): "Optimal Transparency in a Dealership Market with an Application to Foreign Exchange," NBER Working Paper \#4467, September.

Madhavan, A., and S. Smidt (1991): "A Bayesian Model of Intraday Specialist Pricing," Journal of Financial Economics, 30: 99-134.

Manaster, S., and S. Mann (1993): "Life in the Pits: Competitive Marketmaking and Inventory Control," mimeo, University of Utah, May.

O'Hara, M. (1994): Market Microstructure Theory, Blackwell Publishers, forthcoming, October.

O'Hara, M., and G. Oldfield (1986): "The Microeconomics of Market Making," Journal of Financial and Quantitative Analysis, 21: 361-376.

Reuters Ltd. (1990): "The Reuter Dealing 2000-1 Service: User Guide, Version 3," London: Reuters Ltd.

Roell, A. (1990): "Dual-Capacity Trading and the Quality of the Market," Journal of Financial Intermediation, 1: 105-124.

Stoll, H. (1989): "Inferring the Components of the Bid-Ask Spread: Theory and Empirical Tests," Journal of Finance, 44: 115-134. 


\section{Appendix}

Derivation of the Statistic $\mathrm{Z}_{\mathrm{jt}}$ in Equation (4)

Beginning with equation (3):

$$
\begin{aligned}
& \mathrm{Q}_{\mathrm{jt}}=\theta\left(\mu_{\mathrm{jt}}-\mathrm{P}_{\mathrm{it}}\right)+\mathrm{X}_{\mathrm{jt}} \\
\Rightarrow & \mathrm{Q}_{\mathrm{jt}} / \theta+\mathrm{P}_{\mathrm{it}}=\mu_{\mathrm{jt}}+\mathrm{X}_{\mathrm{jt}} / \theta \\
\Rightarrow \quad & \mathrm{Q}_{\mathrm{jt}} / \theta+\mathrm{P}_{\mathrm{it}}=\lambda \mathrm{S}_{\mathrm{t}}+(1-\lambda) \mathrm{C}_{\mathrm{jt}}+\mathrm{X}_{\mathrm{jt}} / \theta \quad \text { where } \lambda \equiv \sigma_{\omega}^{2} /\left(\sigma_{\eta}^{2}+\sigma_{\omega}^{2}\right) \\
\Rightarrow \quad & \mathrm{Q}_{\mathrm{jt}} / \theta+\mathrm{P}_{\mathrm{it}}-\lambda \mathrm{S}_{\mathrm{t}}=(1-\lambda)\left(\mathrm{V}_{\mathrm{t}}+\tilde{\omega}_{\mathrm{jt}}\right)+\tilde{\mathrm{X}}_{\mathrm{jt}} / \theta \quad \text { since } \mathrm{C}_{\mathrm{jt}}=\mathrm{V}_{\mathrm{t}}+\tilde{\omega}_{\mathrm{jt}} \\
\Rightarrow \quad & \mathrm{Z}_{\mathrm{jt}} \equiv \frac{\mathrm{Q}_{\mathrm{jt}} / \theta+\mathrm{P}_{\mathrm{it}}-\lambda \mathrm{S}_{\mathrm{t}}}{1-\lambda}=\mathrm{V}_{\mathrm{t}}+\tilde{\omega}_{\mathrm{jt}}+[1 / \theta(1-\lambda)] \tilde{\mathrm{X}}_{\mathrm{jt}} .
\end{aligned}
$$

Derivation of the Price Representation in Equation (8)

Beginning with equation (6):

$$
\mathbf{P}_{\mathrm{it}}=\mu_{\mathrm{it}}-\alpha\left(\mathrm{I}_{\mathrm{it}}-\mathrm{I}_{\mathrm{i}}^{*}\right)+\gamma \mathrm{D}_{\mathrm{t}}
$$

we can write:

$$
\begin{array}{rlr}
\mu_{\mathrm{it}} & =\kappa_{\mathrm{k}} \mathrm{S}_{\mathrm{t}}+\left(1-\kappa_{\mathrm{k}}\right) \mathrm{Z}_{\mathrm{jt}} \quad \text { where } \kappa_{\mathrm{k}} \equiv \sigma_{\mathbf{Z k}}^{2} /\left(\sigma_{\mathbf{Z k}}^{2}+\sigma_{\eta}^{2}\right), \mathbf{k}=\mathrm{s}, 1 \\
& =\kappa_{\mathrm{k}} \mathrm{S}_{\mathrm{t}}+\left[\frac{1-\kappa_{\mathrm{k}}}{1-\lambda}\right]\left[\mathrm{Q}_{\mathrm{jt}} / \theta+\mathrm{P}_{\mathrm{it}}-\lambda \mathrm{S}_{\mathrm{t}}\right] &
\end{array}
$$




$$
\begin{aligned}
& =\kappa_{\mathbf{k}} S_{t}-\left[\frac{\lambda\left(1-\kappa_{k}\right)}{1-\lambda}\right] S_{t}+\left[\frac{1-\kappa_{k}}{1-\lambda}\right]\left[Q_{j t} / \theta+P_{i t}\right] \\
& =\left[\kappa_{k}-\frac{\lambda\left(1-\kappa_{k}\right)}{1-\lambda}\right] S_{t}+\left[\frac{1-\kappa_{k}}{1-\lambda}\right]\left[Q_{j t} / \theta+P_{i t}\right] \\
& \equiv \phi_{k} S_{t}+\left(1-\phi_{k}\right)\left[Q_{j t} / \theta+P_{i t}\right], \quad \mathbf{k}=8,1 \text { since }\left[\kappa_{k}-\frac{\lambda\left(1-\kappa_{k}\right)}{1-\lambda}\right]+\left[\frac{1-\kappa_{k}}{1-\lambda}\right]=1
\end{aligned}
$$

Note also that $0<\phi_{k}<1$ since $0<\kappa_{k}<1,0<\lambda<1$, and $\kappa_{k}>\lambda$ for both $k=s$ and $k=1$. Each of these properties follows from the definitions of $\kappa_{\mathrm{k}}$ and $\lambda$ and the fact that $\sigma_{\mathrm{Zj}}^{2}=\sigma_{\omega}^{2}+[\theta(1-\lambda)]^{-2} \sigma_{\mathrm{X}}^{2}$

Substituting this expression for $\mu_{\mathrm{it}}$ into equation (6) yields:

$$
\begin{aligned}
\mathrm{P}_{\mathrm{it}} & =\phi_{\mathrm{k}} \mathrm{S}_{\mathrm{t}}+\left(1-\phi_{\mathrm{k}}\right)\left[\mathrm{Q}_{\mathrm{jt}} / \theta+\mathrm{P}_{\mathrm{it}}\right]-\alpha\left(\mathrm{I}_{\mathrm{it}}-\mathrm{I}_{\mathrm{i}}^{*}\right)+\gamma \mathrm{D}_{\mathrm{t}} \\
\Rightarrow \quad \mathrm{P}_{\mathrm{it}} & =\mathrm{S}_{\mathrm{t}}+\left[\frac{1-\phi_{\mathrm{k}}}{\phi_{\mathbf{k}} \theta}\right] \mathbf{Q}_{\mathrm{jt}}-\left[\frac{\alpha}{\phi_{k}}\right]\left(\mathrm{I}_{\mathrm{it}}-\mathrm{I}_{\mathrm{i}}^{*}\right)+\left[\frac{\gamma}{\phi_{\mathrm{k}}}\right] \mathrm{D}_{\mathrm{t}}
\end{aligned}
$$




\section{Table 1}

Overview Statistics

August 3-7, 1992

\section{Direct}

Brokered

(1) Average \# transactions daily
(a) incoming

190

170

(b) outgoing

20

(2) Average value transactions daily

$\$ 0.8$ B

$\$ 0.65 \mathrm{~B}$

(a) incoming

$\$ 0.15 \mathrm{~B}$

(b) outgoing

(3) Median transaction size
(a) incoming
(b) outgoing

$\$ 3 \mathrm{M}$

\$3 M

$\$ 5 \mathrm{M}$

(4) Average \# quotes daily

924

$\begin{array}{ll}\text { (a) made } & 502 \\ \text { (b) received } & 422\end{array}$

(5) Median quoted spread: Dealt

DM 0.0003
(a) made
(b) received

DM 0.0003

DM 0.0003

(6) Median quoted spread: Not Dealt

DM 0.0003

(a) made

DM 0.0003

(b) received

DM 0.0005

* Data for the dealer's direct (inter-dealer) quotes and transactions are from the Reuters Dealing 2000-1 communications. Incoming refers to transactions initiated by another dealer; outgoing refers to transactions initiated by our dealer. Made refers to quotes made by our dealer; received refers to quotes received by our dealer. The trades in these two columns reflect more than $95 \%$ of this dealer's trading; the trades that make up the remainder are executed either (i) over the phone, (ii) with a non-dealer customer, or (iii) in the futures market (IMM). Data for the dealer's brokered transactions are from the dealer's position sheets; it is not possible to identify the aggressor from these data. The dealer's trading day begins at 8:30 AM Eastern Standard Time, and ends around 1:30 PM on average. 


\section{Table 2}

Benchmark Results

(11)

$$
\Delta \mathrm{P}_{\mathrm{it}}=\beta_{0}+\beta_{1} \mathrm{Q}_{\mathrm{jt}}+\beta_{2} \mathrm{I}_{\mathrm{it}}+\beta_{3} \mathrm{I}_{\mathrm{it}-1}+\beta_{4} \mathrm{D}_{\mathrm{t}}+\beta_{5} \mathrm{D}_{\mathrm{t}-1}+\epsilon_{\mathrm{it}}
$$

$\begin{array}{lllllll}\beta_{0} & \beta_{1} & \beta_{2} & \beta_{3} & \beta_{4} & \beta_{5} & \mathrm{R}^{2}\end{array}$

Estimated

$$
-1.37
$$

Predicted

$$
>0
$$

$<0$

$>0$

$>0$

$<0$

* $T$-statistics in parentheses. $\Delta \mathrm{P}_{\text {it }}$ is the change in the transaction price $(\mathrm{DM} / \$)$ from $t-1$ to $t$. $Q_{j t}$ is the dollar quantity transacted directly at dealer i's quoted prices, positive for buyer-initiated trades (i.e. effected at the offer) and negative for seller-initiated trades (at the bid). $I_{t}$ is $i^{\prime}$ s position at the end of period $t . D_{t}$ is an indicator variable with value 1 if the trade is buyer-initiated, and value -1 if seller-initiated. The units of $Q_{j t}, I_{i t}$, and $I_{i t-1}$ are such that a coefficient of unity implies a price impact of DM0.0001 for every $\$ 10$ million. The units of the indicator variable $D_{t-1}$ are such that a coefficient of 10 implies $D M 0.0002 / \$$ between bid and offer at quantity zero. Estimated using OLS, with heteroskedasticity- and autocorrelationconsistent (first-order) standard errors. Sample: August 3-7, 1992, 842 observations. 


\section{Table 3}

Is order-flow less informative when inter-transaction time is short?

$$
\Delta \mathrm{P}_{\mathrm{it}}=\beta_{0}+\beta_{1 \mathrm{t}} \mathrm{Q}_{\mathrm{jt}}+\beta_{1 \mathrm{t}}^{\prime} \mathrm{Q}_{\mathrm{jt}}+\beta_{2} \mathrm{I}_{\mathrm{it}}+\beta_{3} \mathrm{I}_{\mathrm{it}-1}+\beta_{4} \mathrm{D}_{\mathrm{t}}+\beta_{5} \mathrm{D}_{\mathrm{t}-1}+\epsilon_{\mathrm{it}}
$$

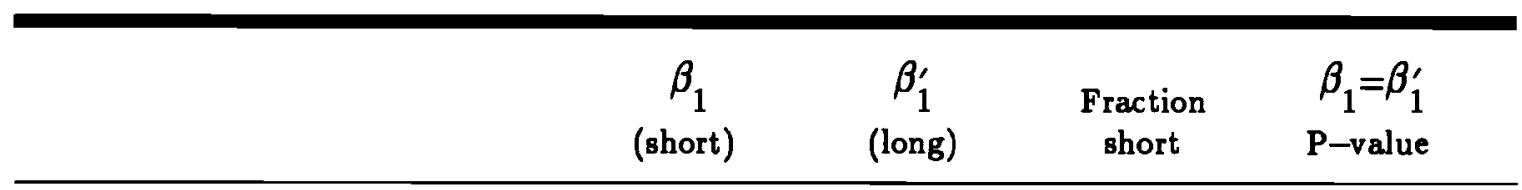

Inter-transaction time short if:

Less than 1 minute

Less than 2 minutes
$-0.01$

$(-0.01)$

0.76

(1.63)
2.20 $\frac{262}{842}$

842

$\underline{506}$

842
0.000

0.009

* $\mathrm{T}$-statistics in parentheses. The coefficient $\beta_{1}$ measures the information effect of trades for which the time from the previous transaction is short $\left(s_{t}=1\right.$ and $l_{t}=0$ in the equation in the heading), where short is defined in the first column. The coefficient $\beta_{1}^{\prime}$ measures the information effect of those trades for which the time from the previous transaction is long $\left(s_{t}=0, l_{t}=1\right)$, where long is defined as not short. The Fraction short column presents the fraction of observations satisfying the corresponding definition of short inter-transaction times. In each case the remaining observations fall into the long category. The $\mathrm{P}$-value column presents the significance level at which the null $\beta_{1}=\beta_{1}^{\prime}$ can just be rejected. $\Delta \mathrm{P}_{\text {it }}$ is the change in the transaction price $(D M / \$)$ from t-1 to t. $Q_{j t}$ is the dollar quantity transacted directly at dealer $i$ 's quoted prices, positive for buyer-initiated trades (i.e. effected at the offer) and negative for seller-initiated trades (at the bid). The units of $Q_{j t}$ are such that $\beta_{1}=1$ implies a price impact of DM 0.0001 for every $\$ 10$ million. $I_{t}$ is $i^{\prime}$ s position at the end of period t. $D_{t}$ is an indicator variable with value 1 if the trade is buyer-initiated, and value -1 if seller-initiated. Estimated using OLS, with heteroskedasticity- and autocorrelation-consistent (first-order) standard errors. Sample: August 3-7, 1992, 842 observations. 


\section{Table 4}

Is clumped order-flow less informative when transactions follow the same direction?

$$
\Delta \mathrm{P}_{\mathrm{it}}=\beta_{0}+\beta_{1} \mathrm{~s}_{\mathrm{t}} \mathrm{Q}_{\mathrm{jt}}+\beta_{1}^{\prime} \mathrm{o}_{\mathrm{t}} \mathrm{Q}_{\mathrm{jt}}+\beta_{1}^{\prime \prime} \mathrm{l}_{\mathrm{t}} \mathrm{Q}_{\mathrm{jt}}+\beta_{2} \mathrm{I}_{\mathrm{it}}+\beta_{3} \mathrm{I}_{\mathrm{it}-1}+\beta_{4} \mathrm{D}_{\mathrm{t}}+\beta_{5} \mathrm{D}_{\mathrm{t}-1}+\epsilon_{\mathrm{it}}
$$

\begin{tabular}{|c|c|c|c|c|c|}
\hline $\begin{array}{c}\beta_{1} \\
\text { (short } \\
\& \\
\text { same) }\end{array}$ & $\begin{array}{c}\beta_{1}^{\prime} \\
\text { (short } \\
\& \\
\text { opposite) }\end{array}$ & $\begin{array}{c}\beta_{1}^{\prime \prime} \\
\text { (long) }\end{array}$ & $\begin{array}{c}\text { Fraction } \\
\text { short } \\
\& \\
\text { same }\end{array}$ & $\begin{array}{c}\text { Fraction } \\
\text { short } \\
\& \\
\text { opposite }\end{array}$ & $\begin{array}{l}\beta_{1}=\beta_{1}^{\prime} \\
\mathrm{P} \text {-value }\end{array}$ \\
\hline $\begin{array}{c}-0.06 \\
(-0.11)\end{array}$ & $\begin{array}{c}1.90 \\
(3.01)\end{array}$ & $\begin{array}{c}2.64 \\
(3.46)\end{array}$ & $\frac{276}{842}$ & $\frac{230}{842}$ & 0.009 \\
\hline
\end{tabular}

* $T$-statistics in parentheses. The coefficient $\beta_{1}$ measures the information effect of trades that (i) have short inter-transaction times, defined as less than the median of 2 minutes, and (ii) have the same direction of the previous trade $\left(s_{t}=1, o_{t}=0\right.$, and $l_{t}=0$ in the equation in the heading). The coefficient $\beta_{1}^{\prime}$ measures the information effect of trades that (i) have short inter-transaction times, defined as less than the median of 2 minutes, and (ii) have the opposite direction of the previous trade $\left(s_{t}=0, o_{t}=1, l_{t}=0\right)$. The coefficient $\beta_{1}^{\prime \prime}$ measures the information effect of trades that have long inter-transaction times, defined as greater than or equal to the median of 2 minutes $\left(s_{t}=0\right.$, $\left.o_{t}=0, l_{t}=1\right)$. The Fraction short \& same column presents the fraction of observations satisfying the corresponding definition of short \& same (similarly for the Fraction short \& opposite column). The remaining $336 / 842$ observations fall into the long category. The P-value column presents the significance level at which the null $\beta_{1}=\beta_{1}^{\prime}$ can just be rejected. $\Delta \mathrm{P}$ it is the change in the transaction price $(D M / \$)$ from $t-1$ to $t . Q_{j t}$ is the dollar quantity transacted directly at dealer $i$ 's quoted prices, positive for buyer-initiated trades (i.e. effected at the offer) and negative for seller-initiated trades (at the bid). The units of $Q_{\text {jt }}$ are such that $\beta_{1}=1$ implies a price impact of DM0.0001 for every $\$ 10$ million. $I_{t}$ is $i^{\prime} s$ position at the end of period $t$. $D_{t}$ is an indicator variable with value 1 if the trade is buyer-initiated, and value -1 if seller-initiated. Estimated using OLS, with heteroskedasticity- and autocorrelation-consistent (first-order) standard errors. Sample: August 3-7, 1992, 842 observations. 


\section{$\underline{\text { Table } 5}$}

Is order-flow more informative when quoting intensity is high?

$$
\Delta \mathrm{P}_{\mathrm{it}}=\beta_{0}+\beta_{1} \mathrm{~h}_{\mathrm{t}} \mathrm{Q}_{\mathrm{jt}}+\beta_{1 \mathrm{t}}^{\prime} \mathrm{Q}_{\mathrm{jt}}+\beta_{2} \mathrm{I}_{\mathrm{it}}+\beta_{3} \mathrm{I}_{\mathrm{it}-1}+\beta_{4} \mathrm{D}_{\mathrm{t}}+\beta_{5} \mathrm{D}_{\mathrm{t}-1}+\epsilon_{\mathrm{it}}
$$

\begin{tabular}{cccc}
\hline$\beta_{1}$ & $\beta_{1}^{\prime}$ & Fraction & $\beta_{1}=\beta_{1}^{\prime}$ \\
(high) & (low) & P-value \\
\hline
\end{tabular}

Quoting intensity high if:

$\geq 3$ intervening quotes per minute

$\geq 4$ intervening quotes per minute

* $\mathrm{T}$-statistics in parentheses. The coefficient $\beta_{1}$ measures the information effect of those trades occurring when quoting intensity is high, $\left(h_{t}=1, l_{t}=0\right)$, where high intensity is defined in the first column by the total number of quotes - both made and received - since the previous incoming transaction. The coefficient $\beta_{1}^{\prime}$ measures the information effect of those trades occurring when quoting intensity is low $\left(h_{t}=0, l_{t}=1\right)$, where low intensity is defined as not high. The Fraction high column presents the fraction of observations satisfying the corresponding definition of high-intensity quoting. The $\mathrm{P}$-value column presents the significance level at which the null $\beta_{1}=\beta_{1}^{\prime}$ can just be rejected. $\Delta \mathrm{P}_{\text {it }}$ is the change in the transaction price (DM/\$) from $t-1$ to $t$. $Q_{j t}$ is the dollar quantity transacted directly at dealer $i^{\prime} s$ quoted prices, where both are positive for buyer-initiated trades (i.e. effected at the offer) and negative for seller-initiated trades (at the bid). The units of $Q_{j t}$ are such that $\beta_{1}=1$ implies a price impact of DM0.0001 for every $\$ 10$ million. $I_{t}$ is $i$ 's position at the end of period t. $D_{t}$ is an indicator variable with value 1 if the trade is buyer-initiated, and value -1 if seller-initiated. Estimated using OLS, with heteroskedasticity- and autocorrelation-consistent (first-order) standard errors. Sample: August 3-7, 1992, 842 observations. 